\title{
Does the root to shoot ratio show a hormetic response to stress? An ecological and environmental perspective
}

\author{
Evgenios Agathokleous ${ }^{1,2}$ (1) Regina G. Belz ${ }^{3} \cdot$ Mitsutoshi Kitao $^{1} \cdot$ Takayoshi Koike $^{2}$ • \\ Edward J. Calabrese ${ }^{4}$
}

Received: 5 August 2018/Accepted: 13 October 2018/Published online: 10 December 2018

(C) The Author(s) 2018

\begin{abstract}
Root/shoot (R/S) ratio is an important index for assessing plant health, and has received increased attention in the last decades as a sensitive indicator of plant stress induced by chemical or physical agents. The R/S ratio has been discussed in the context of ecological theory and its potential importance in ecological succession, where species follow different strategies for above-ground growth for light or below-ground competition for water and nutrients. We present evidence showing the R/S ratio follows a biphasic dose-response relationship under stress, typical of hormesis. The R/S ratio in response to stress has been widely compared among species and ecological succession classes. It is constrained by a variety of factors such as
\end{abstract}

Project funding: This research was supported by JSPS KAKENHI Grant Number JP17F17102, German Research Foundation (BE4189/ 1-3), the US Air Force [AFOSR FA9550-13-1-0047] and ExxonMobil Foundation [S18200000000256].

The online version is available at http://www.springerlink.com

Corresponding editor: Yu Lei.

Evgenios Agathokleous

evgenios@affrc.go.jp; globalscience@frontier.hokudai.ac.jp

1 Hokkaido Research Center, Forestry and Forest Products Research Institute (FFPRI), Forest Research and Management Organization, 7 Hitsujigaoka, Sapporo, Hokkaido 062-8516, Japan

2 Research Faculty of Agriculture, Hokkaido University, Kita 9 Nishi 9, Sapporo, Hokkaido 060-8589, Japan

3 Agroecology Unit, Hans-Ruthenberg Institute, University of Hohenheim, Garbenstraße 13, 70599 Stuttgart, Germany

4 Department of Environmental Health Sciences, Morrill I, N344, University of Massachusetts, Amherst, MA 01003, USA ontogeny. Furthermore, the current literature lacks doseresponse studies incorporating the full dose-response continuum, hence limiting scientific understanding and possible valuable application. The data presented provide an important perspective for new-generation studies that can advance current ecological understanding and improve carbon storage estimates by $\mathrm{R} / \mathrm{S}$ ratio considerations. Hormetic response of the R/S ratio can have an important role in forestry for producing seedlings with desired characteristics to achieve maximum health/productivity and resilience under plantation conditions.

Keywords Biological plasticity - Biphasic response . Hormesis · Plant stress $\cdot$ Root/shoot ratio

\section{Introduction}

In a world of changing environments where plants are dealing with stress, dose-response studies serve as a tool for assessing and modelling plant stress at various levels. A wide range of scientific disciplines are concerned with plant stress induced by chemical or environmental stressors. Likewise, policy making faces the challenge to set environmental standards and derive critical levels/loads for protecting vegetation and ecosystems against environmental stress such as surface ozone and nitrogen deposition (Payne et al. 2013; Anav et al. 2016; Sicard et al. 2017; Agathokleous et al. 2019). At the same time, the field of dose-response studies is more and more suggesting hormesis as a fundamental dose-response phenomenon (Fig. 1). While hormetic dose-responses of animals received particular attention from the early 2000s, this was not the case for plants. However, in recent years hormetic dose-responses of plants have been shown for a variety of 


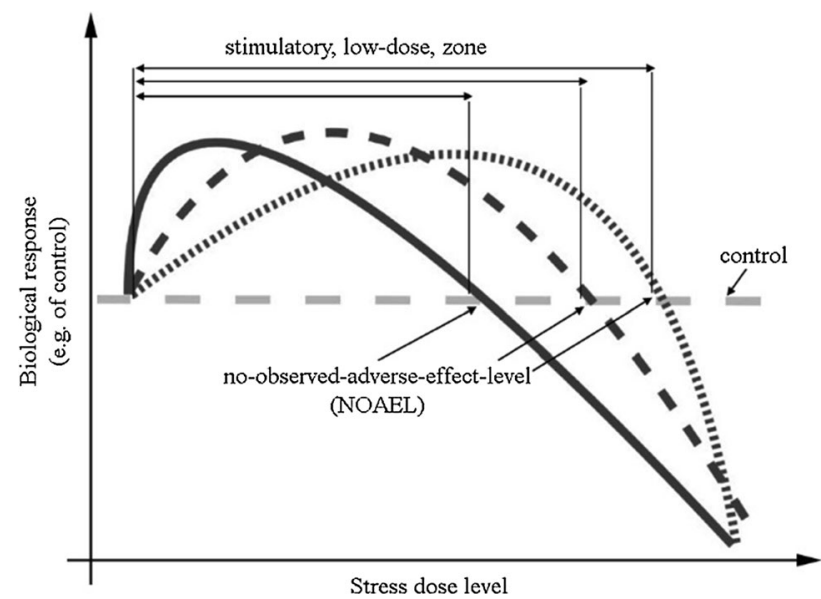

Fig. 1 Hypothetical examples of hormetic dose-response relationships. Note: Exposure of organisms to a wide range of narrowlyspaced stress doses/concentrations generates biphasic dose-response relationships with biological stimulation in response to low doses and inhibition by high doses. The stimulatory zone spans from the lowest, stimulatory dose to the dose where the no-observed-adverse-effectlevel (NOAEL) occurs. The width of the stimulatory dose varies, e.g., with the experimental design (e.g., number of doses incorporated). Inhibition of biological response begins after (to the right) of the NOAEL

stressors and endpoints (Cedergreen et al. 2007; Calabrese and Blain 2009; Cedergreen et al. 2009; Belz and Duke 2017; Belz and Piepho 2017; Agathokleous et al. 2018a, b, c; Agathokleous and Kitao 2018; Sugai et al. 2018). Of particular importance to the field of hormesis is the recent action of the US Environmental Protection Agency examining the possibility to incorporate $U$-shaped, $J$-shaped, and bell-shaped models, typical examples of hormesis in the risk assessment process (US EPA 2018).

An important matter regarding plant health is whether an imbalance between the epigeous and hypogeous growth (root/shoot ratio, R/S) occurs under stress. Therefore, an important index for assessing plant health is the $\mathrm{R} / \mathrm{S}$ ratio, estimated especially in the form of dry weight $\left(R_{d w} / S_{d w}\right.$ ratio), or to a lesser extent by length $\left(\mathrm{R}_{\text {length }} / \mathrm{S}_{\text {length }}\right.$ ratio). Changes in $R_{d w} / S_{d w}$ ratios have been widely observed under stress, however the results are inconsistent and it remains uncertain if $R_{d w} / S_{d w}$ ratios increase, decrease, or remain unaffected under certain conditions of stress (Wilson 1988; Agren and Franklin 2003; Koike et al. 2003; Grantz et al. 2006; Agathokleous et al. 2016). Despite extensive reviews of the topic, the R/S ratio has never been put into the context of dose-response studies incorporating the full dose-response continuum and thus hormesis. To this end, this commentary examines data from several peerreviewed articles to illustrate $\mathrm{R} / \mathrm{S}$ ratio responses to stress from a biphasic dose-response viewpoint including hormesis.

\section{Hormetic response of root and shoot to stress}

Root biomass/length and/or aboveground biomass/height have been found to display significant stimulation at low doses and inhibition at high doses upon exposure to several chemicals and physical agents in numerous independent experiments and with a variety of annual and perennial plant species (Table 1). However, a stimulatory response in one plant trait does not necessarily correlate or match with a stimulatory response in other plant traits (Duke et al. 2006), and this apparently also applies to the same trait measured on roots and shoots. For example, veterinary antibiotics induced hormetic responses in shoot and root elongation but root (Fig. 2a-d) and shoot (Fig. 2e-h) showed uncoupled low-dose responses, i.e., one endpoint showed significant stimulatory responses while the other might not (Pan and Chu 2016). Hormetic-like responses of shoot or root elongation were also observed for the antibiotic enrofloxacin affecting tamarillo plants (Cyphomandra betacea (Cav.) Sendtn.) or sulfadiazine sodium affecting wheat plants (Triticum aestivum L.) (Jin et al. 2009). Experiments with a variety of eastern tree species showing differential responses of $R_{d w}$ and $S_{d w}$ to atmospheric ozone exposure (Fig. 3a-d) (Kress and Skelly 1982) further support root and shoot imbalances. Hence, there is accumulated evidence from several independent experiments suggesting that hormetic responses of root biomass/length and/or aboveground biomass/height to stress is a general, but partly uncoupled phenomenon, independent of species and stress-inducing agent (Calabrese and Blain 2011; Table 1). At low stress doses, increased photosynthetic carbon gain and increased carbon partitioning into roots can be apparent. At high stress doses, reduced photosynthetic carbon gain by stomatal closure can result in a decrease in root biomass/elongation. Thus, there can be two (or more) responses to stress with different directions, depending on the dose of the stress. Based on these imbalances, it is suggested that the $\mathrm{R} / \mathrm{S}$ ratio is also changing in a dose-dependent manner, thus having potential to affect ecological risk assessment and carbon storage estimates (Durigan et al. 2012; Luo et al. 2013). Therefore, this discussion raises the question of whether the $\mathrm{R} / \mathrm{S}$ ratio $\left(\mathrm{R}_{\mathrm{dw}} / \mathrm{S}_{\mathrm{dw}}\right.$ or $\left.\mathrm{R}_{\text {length }} / \mathrm{S}_{\text {height }}\right)$ displays a hormetic response to stress, a matter of biological, ecological, and environmental significance.

\section{Hormetic response of $\mathrm{R} / \mathrm{S}$ ratio to stress}

A literature analysis revealed that the $\mathrm{R} / \mathrm{S}$ ratio displays hormetic responses for a variety of stressors and species. For example, a hormetic-like response of $\mathrm{R}_{\mathrm{dw}} / \mathrm{S}_{\mathrm{dw}}$ to 
Table 1 Examples of empirical data suggesting biphasic dose-response relationships of root biomass/length and above-ground biomass/height

Empirical data $\quad$ Reference

Type of plants

Cereals

Grasses

Legumes

Vegetables

Weeds

Trees

Medicinal crops and trees

Inducing agents

Herbicides

Anthropogenic environmental contaminants (soil and air contaminants)

Nutrients

Other natural and synthetic chemicals
Jin et al. (2009), Wang et al. (2010), Xie et al. (2010, 2011), Minden et al. (2017)

Liu et al. (2008), Minden et al. (2017), Agathokleous et al. (2019)

Diatloff et al. (1995), Liang and Wang (2013)

Belz et al. (2008, 2018), Belz and Leberle (2012), Belz and Piepho (2013, 2017), Pan and Chu (2016), Minden et al. (2017), Bastien et al. (2018), Agathokleous et al. (2019)

He and Loh (2000), Cedergreen (2008), Minden et al. (2017), Li et al. (2017), Agathokleous et al. (2018c)

Jin et al. (2009), Wu et al. (2014), Chen et al. (2018), Cap and Eşen (2018), Agathokleous et al. (2019)

Gorni and Pacheco (2016), Ma et al. (2017), Waman et al. (2018)

Belz et al. (2008, 2018), Cedergreen (2008), Belz and Leberle (2012), Belz and Piepho (2017), Cap and Eşen (2018)

Diatloff et al. (1995), He and Loh (2000), Liu et al. (2008), Jin et al. (2009), Migliore et al. (2010a, 2010b), Xie et al. (2010, 2011), Liang and Wang (2013), Pan and Chu (2016), Minden et al. (2017), Ma et al. (2017), Agathokleous (2018), Agathokleous et al. (2018b, d, 2019), Bastien et al. (2018)

Wu et al. (2014), Chen et al. (2018)

Belz et al. (2008, 2018), Belz and Piepho (2013, 2017), Gorni and Pacheco (2016), Li et al. (2017), Agathokleous et al. (2018c), Waman et al. (2018) lanthanum (La) was found in soybean (Glycine $\max \mathrm{L} . \mathrm{cv}$. Kennong 18) (Fig. 4a) (Liang and Wang 2013), in tall fescue (Festuca arundinacea Schreb.) (Fig. 4b) (Liu et al. 2008), and in Chinese sage (Salvia miltiorrhiza Bunge) (Fig. 4c) (Zhou et al. 2011). Similar hormetic-like doseresponse relationships of $R_{d w} / S_{d w}$ were found in rapeseed (Brassica napus L.) and in common windgrass (Apera spica-venti (L.) P. Beauv.) in response to the veterinary antibiotic tetracycline (Fig. 5a) (Minden et al. 2017), in Eucalyptus urophylla $\times$ E. camaldulensis in response to phosphorus availability (Fig. 5b) (Wu et al. 2014), in yarrow (Achillea millefolium L.) exposed to salicylic acid (Fig. 5c) (Gorni and Pacheco 2016), in ryegrass (Lolium perenne L.) in response to soil moisture in two different growing conditions (Fig. 5d) and in clover (Trifolium repens $\mathrm{L}$.) in response to soil nitrogen availability in four different growing conditions (Fig. 5e and f) (Davidson 1969b).

In most of the examples, an inverse $U$-shaped doseresponse relationship was found for $\mathrm{R}_{\mathrm{dw}} / \mathrm{S}_{\mathrm{dw}}$ (Figs. 4, 5a-d, f), suggesting higher root biomass relative to shoot biomass under low-dose stress and higher shoot biomass relative to root biomass under high-dose stress. However, in some examples, a non-inverse $U$-shaped hormetic dose-response relationship was found for $\mathrm{R}_{\mathrm{dw}} / \mathrm{S}_{\mathrm{dw}}$ (Fig. 5e, f). Such noninverse $U$-shaped dose-response relationships were also found in little seed canary grass (Phalaris minor Retz.) and wild oat (Avena fatua L.) after spraying with the herbicide fenoxaprop-P-ethyl (Fig. 6a) (Abbas et al. 2016), and in tall fescue (Festuca arundinacea Schreb.), ryegrass and other grass species (Vulpia sp.) in response to soil temperatures (Fig. 6b) (Davidson 1969a).

The elongation ratio $R_{\text {length }} / S_{\text {height }}$ can be interpreted in the same way. This is shown by Abbas et al. (2016) where $\mathrm{R}_{\mathrm{dw}} / \mathrm{S}_{\mathrm{dw}}$ (Fig. 6a) is in full agreement with $\mathrm{R}_{\text {length }} / \mathrm{S}_{\text {height }}$ (Fig. 7a). Additional examples of hormesis in $\mathrm{R}_{\text {length }} / \mathrm{S}_{\text {height }}$ were found in durum wheat (Triticum durum Desf.) in response to $\mathrm{KNO}_{3}$ (Fig. 7b), rare earth elements nitrate (Fig. 7c), and lanthanum nitrate (Fig. 7d) (d'Aquino et al. 2009). For all inverted- $U$-shaped hormetic findings presented here, the maximum stimulatory $\mathrm{R} / \mathrm{S}$ response to low-dose stress was up to 2.4-fold of the control. This is in agreement with the plant Hormesis Database where the maximum stimulatory response to low-dose stress is commonly below twofold the control response across endpoints, species, and stress-inducing agents (Calabrese and Blain 2009).

If an optimal $\mathrm{R} / \mathrm{S}$ ratio is defined as the equal growth limitation of root and shoot by stress (Aikio and Mari Markkola 2002), then hormetic R/S dose-responses suggest the paradox that optimal R/S occurs on the one hand before the threshold of the hormetic dose zone, i.e., where low-dose stimulatory response starts, and on the other hand at the no-observed-adverse-effect-level (NOAEL or else 

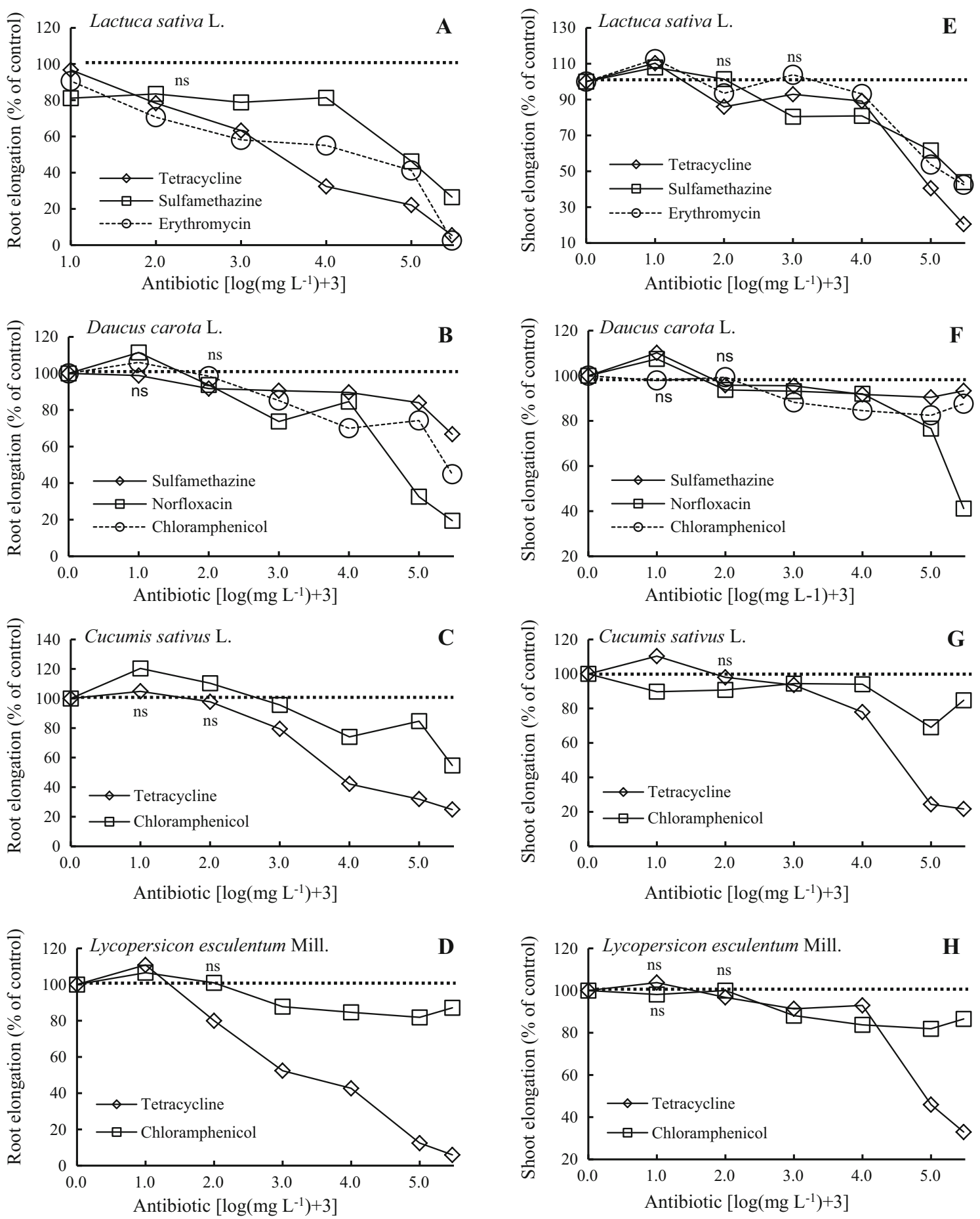

Fig. 2 Examples of antibiotic-induced hormesis: Root elongation (a-d) versus shoot elongation (e-h) (Pan and Chu 2016). "ns" above means indicate the difference from the control response is not statistically significant, whereas no sign indicates statistical

significance. For illustration purposes, in some cases with wide range of dose levels, the concentrations were transformed to logarithm (log) and when needed a constant was added

limited-dose-for-stimulation LDS), where hormesis ends and high-dose response starts. However, in order to derive these toxicological estimates from dose-response data, modeling of the hormetic curves is necessary. The next section introduces how hormetic curves can be modelled

and provides selected examples of significantly modelled hormetic curves for $\mathrm{R}, \mathrm{S}$, and $\mathrm{R} / \mathrm{S}$ data. 

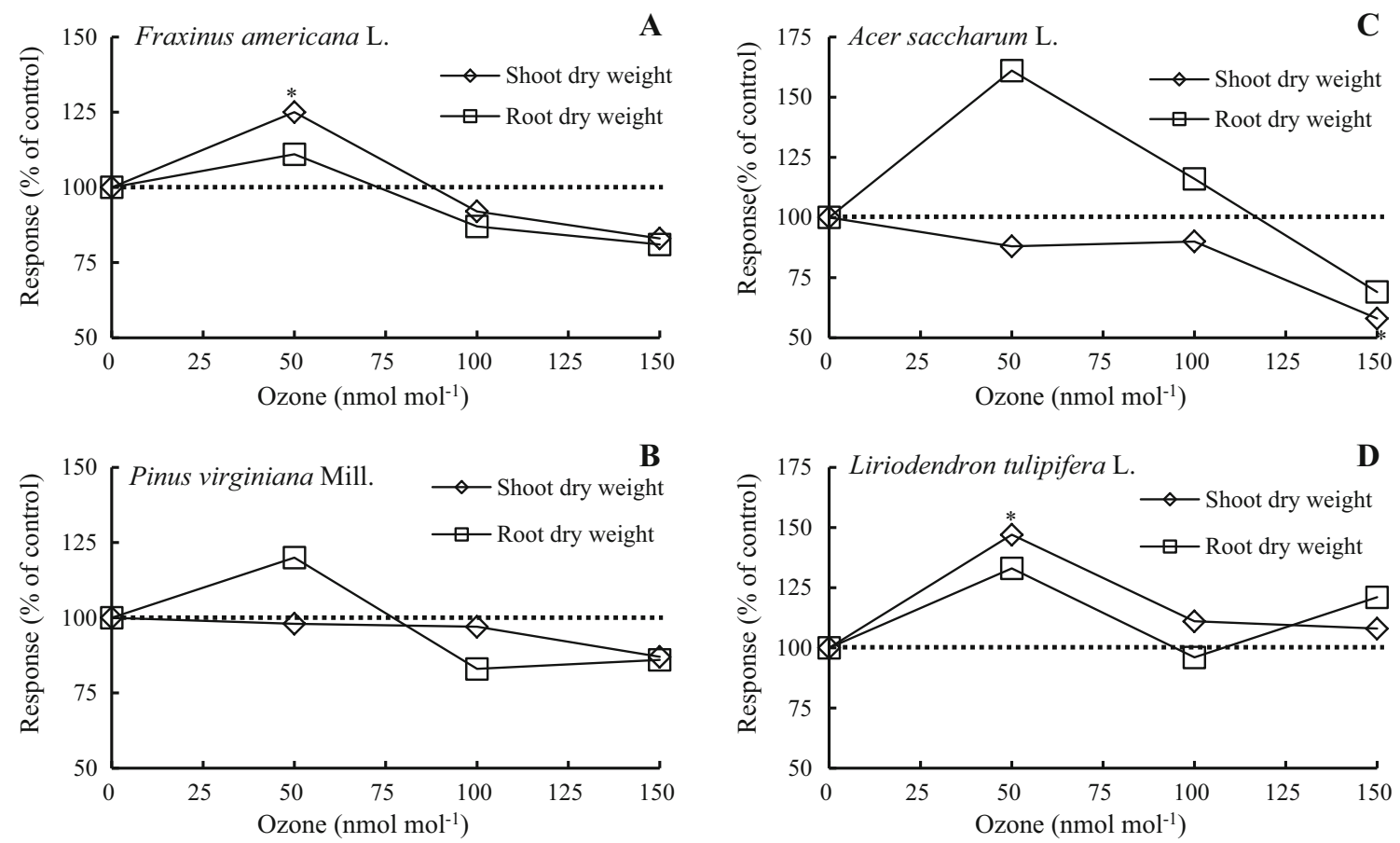

Fig. 3 Hormetic-like examples of uncoupled root dry weight and shoot dry weight responses to stress. Asterisks above or below means indicate the difference from the control response is statistically significant, whereas no sign indicates no statistical significance (Kress and Skelly 1982)
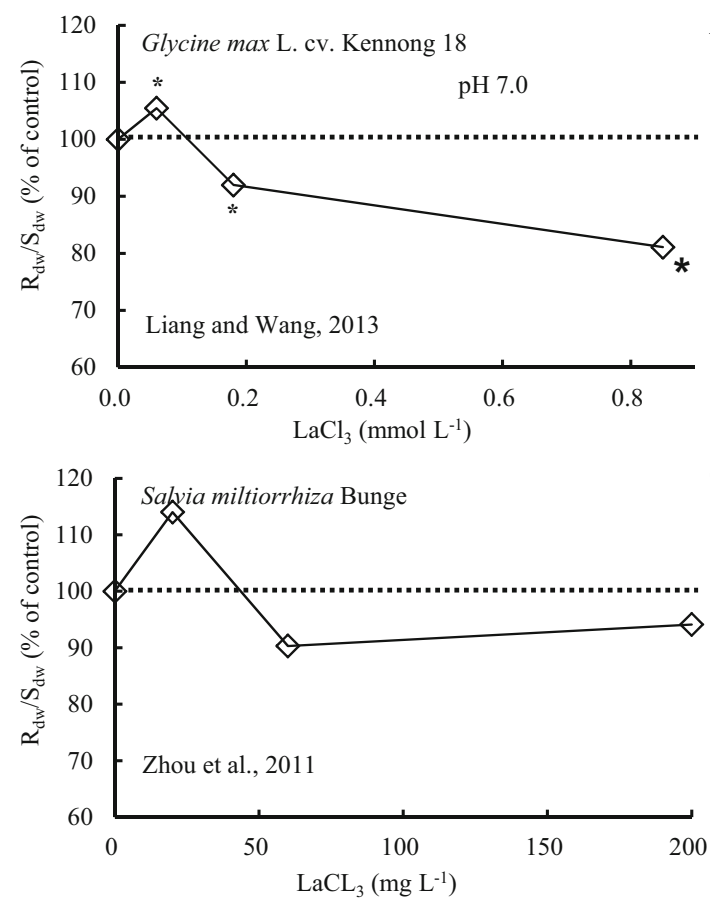

Fig. 4 Typical examples of hormetic-like responses of root dry weight to shoot dry weight ratio $\left(\mathrm{R}_{\mathrm{dw}} / \mathrm{S}_{\mathrm{dw}}\right)$ to the rare earth element lanthanum. Asterisks above or below means indicate the difference from the control response is statistically significant, whereas no sign indicates no statistical significance after hypothesis testing or absence of statistical hypothesis testing. $\mathrm{R}_{\mathrm{dw}} / \mathrm{S}_{\mathrm{dw}}$ data for the compartment

A

C

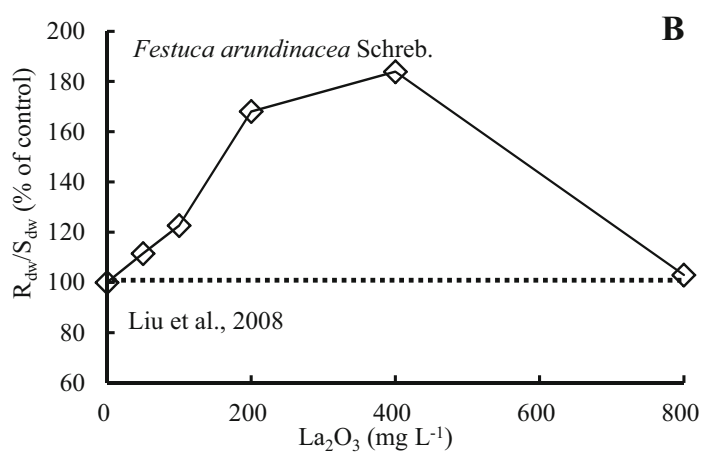

$C$ were calculated based on $\mathrm{R}_{\mathrm{dw}}$ and $\mathrm{S}_{\mathrm{dw}}$ data displayed in the original paper. Note: For Figs. 4, 5, 6 and 7, when needed, dose-response data were estimated from figures of the reviewed articles using image analysis software (Adobe Photoshop CS4 Extended v.11, Adobe Systems Incorporated, CA, USA) 

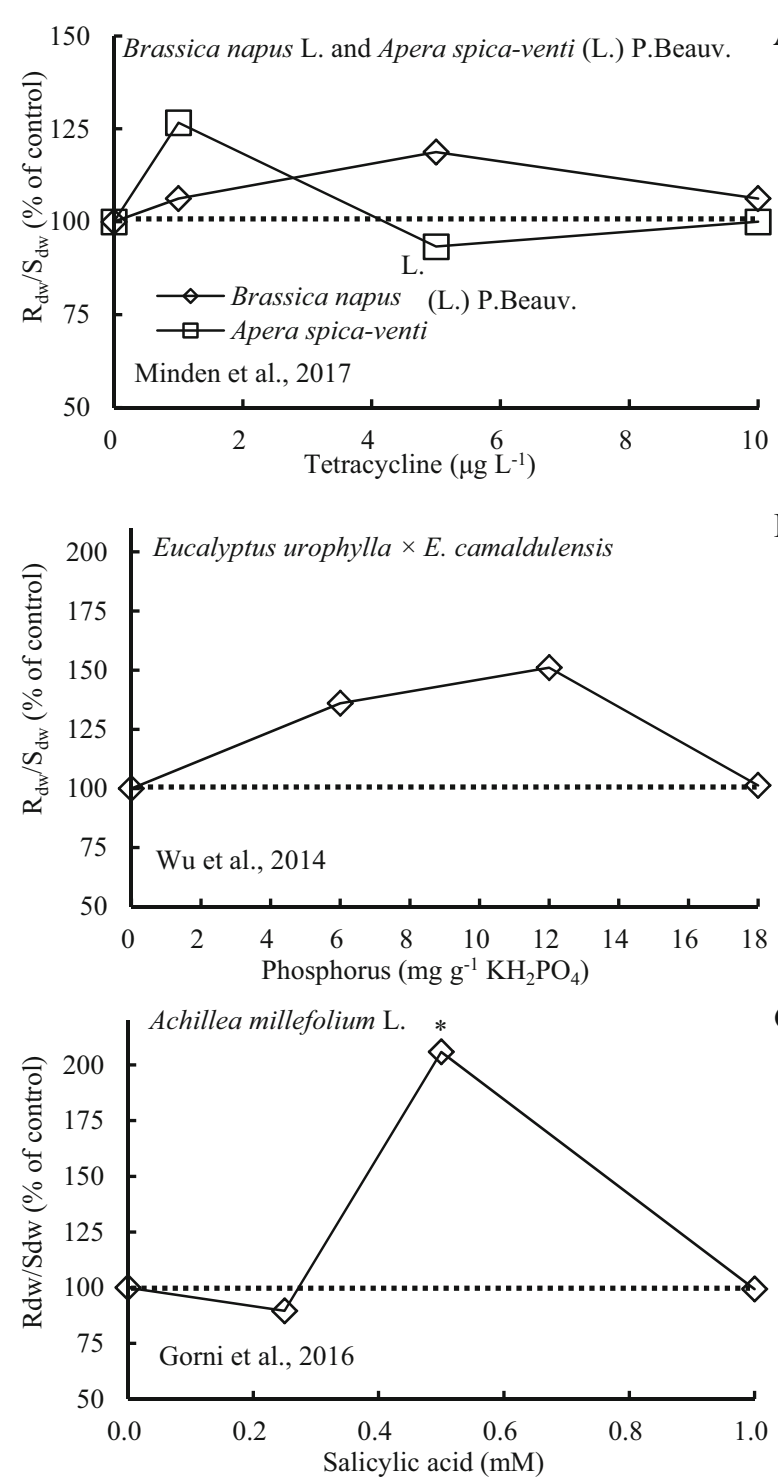

Fig. 5 Typical examples of hormetic-like responses of root dry weight to shoot dry weight ratio $\left(\mathrm{R}_{\mathrm{dw}} / \mathrm{S}_{\mathrm{dw}}\right)$ to stress-inducing agents. Asterisks above or below means indicate the difference from the control response is statistically significant, whereas no sign indicates

\section{Modeling hormetic response of $\mathrm{R} / \mathrm{S}$ ratio to stress}

There are mathematical models available that can quantitatively describe a hormetic dose-response curve, e.g., ecological-limiting-factor models (An et al. 1993; Liu et al. 2011), switching functions (Schabenberger and Birch 2001). However, only two are well-established in plant biology and directly include biologically meaningful parameters or allow to deduce such features: the four-parameter logistic model (Brain and Cousens 1989; Schabenberger et al. 1999), and its expansion in form of the five-parameter logistic Cedergreen model (Cedergreen et al. 2005) (Eqs. 1 and 2).
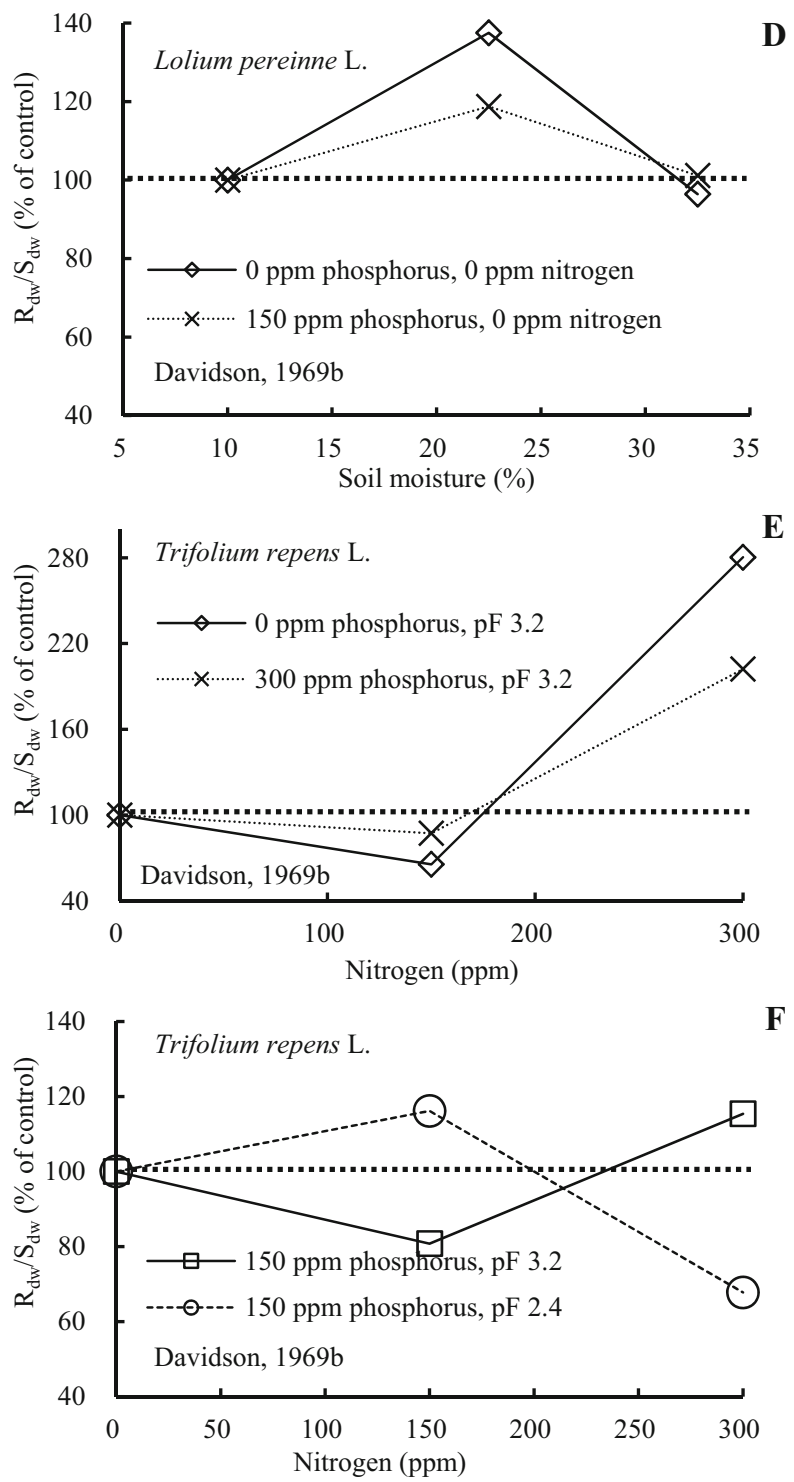

no statistical significance after hypothesis testing or absence of statistical hypothesis testing. $\mathrm{R}_{\text {length }} / \mathrm{S}_{\text {length }}$ data for the compartment $B$ were calculated based on $\mathrm{R}_{\text {length }}$ and $\mathrm{S}_{\text {length }}$ data displayed in the original paper

$E[y \mid x]=c+\frac{d-c+f x}{1+\exp [b \ln (x / e)]}$

$E[y \mid x]=c+\frac{d-c+f \exp \left(-1 / x^{a}\right)}{1+\exp [b \ln (x / e)]}$

where $c$ shows the response at indefinitely high doses; $d$ the expected response of the control; $f$ the rate of increase in the response at low-level doses; the size of $a$ determines the steepness of the curve before the maximal hormetic effect, and the size of $b$ does so thereafter. Parameter $e$ has no straightforward biological meaning (Cedergreen et al. 2005). 


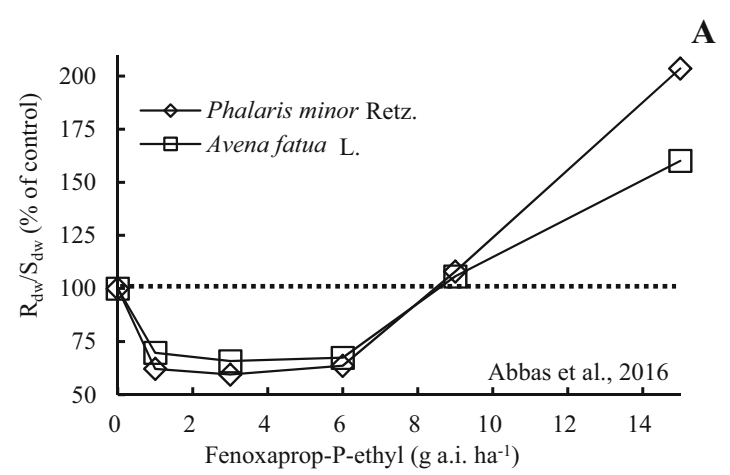

Fig. 6 Typical examples of hormetic-like responses of root dry weight to shoot dry weight ratio $\left(\mathrm{R}_{\mathrm{dw}} / \mathrm{S}_{\mathrm{dw}}\right)$ to stress-inducing agents. Asterisks above or below means indicate the difference from the control response is statistically significant, whereas no sign indicates no statistical significance after hypothesis testing or absence of
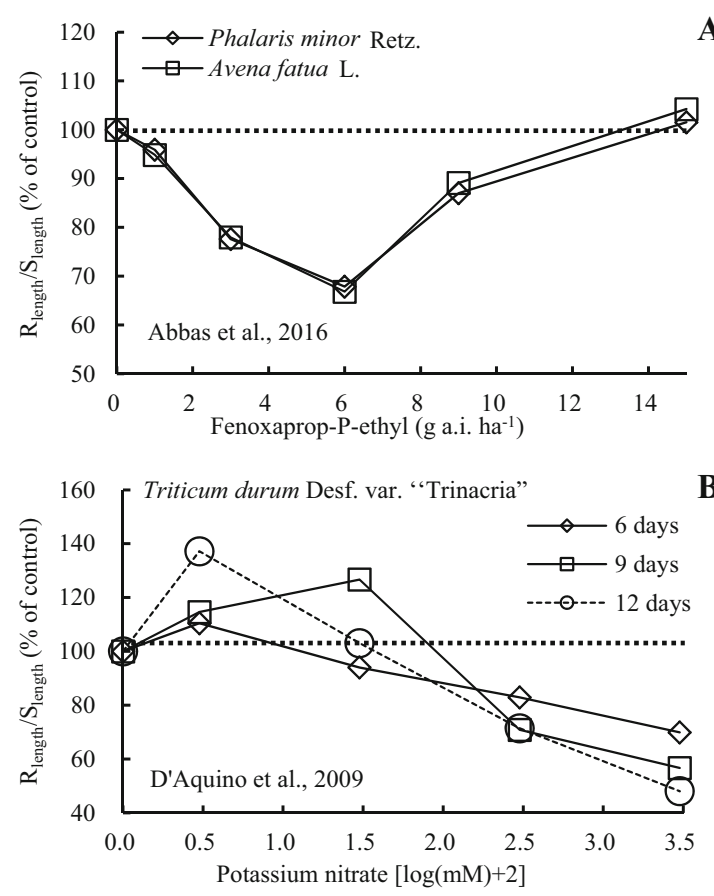

Fig. 7 Typical examples of hormetic-like responses of root length to above-ground height ratio $\left(\mathrm{R}_{\text {length }} / \mathrm{S}_{\text {length }}\right)$ to stress-inducing agents. $\mathrm{R}_{\text {length }} / \mathrm{S}_{\text {length }}$ data were calculated based on $\mathrm{R}_{\text {length }}$ and $\mathrm{S}_{\text {length }}$ data

The dose level where the response is inhibited by half $\left(\mathrm{IC}_{50}\right.$ or $\mathrm{EC}_{50}$ or $\left.\mathrm{ED}_{50}\right)$ and several other quantitative hormetic features (i.e., the dose where hormesis is maximum or the maximum amplitude of hormesis) cannot be directly derived from the original model equations, but can be modeled using re-parameterizations of the original functions (Schabenberger et al. 1999; Belz and Piepho 2012, 2015). Hormetic dose-responses can vary, especially

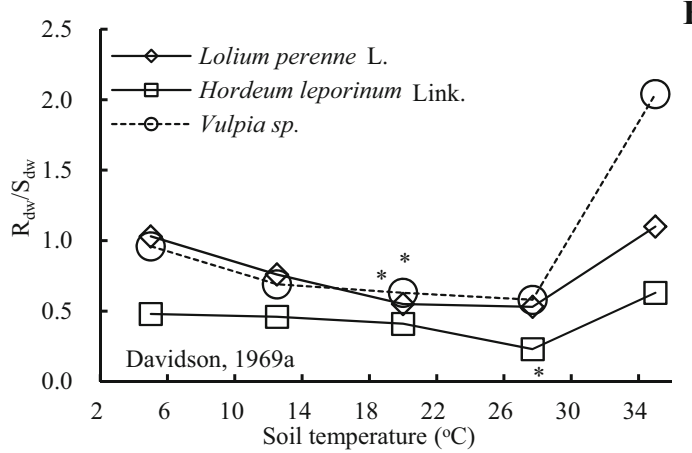

B

statistical hypothesis testing. $\mathrm{R}_{\text {length }} / \mathrm{S}_{\text {length }}$ data for the compartment $A$ were calculated based on $\mathrm{R}_{\text {length }}$ and $\mathrm{S}_{\text {length }}$ data displayed in the original paper. The unit $\mathrm{g}$ a.i. $\mathrm{ha}^{-1}$ stands for grams of active pharmaceutical ingredient dose per hectare
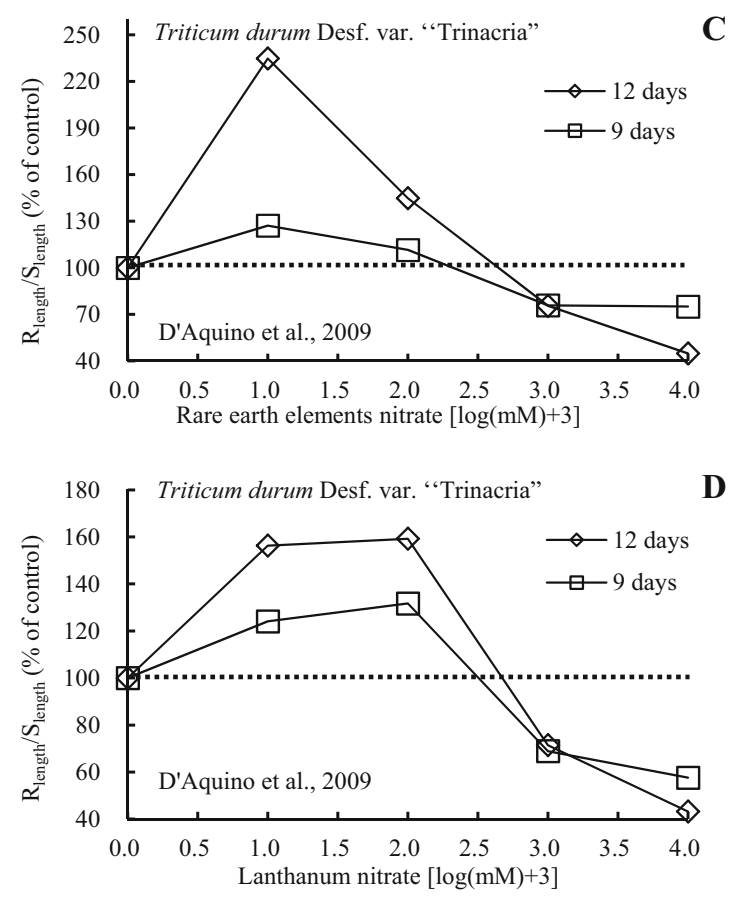

displayed in the reference papers. The unit $\mathrm{g}$ a.i. $\mathrm{ha}^{-1}$ stands for grams of active ingredient per hectare

with respect to the width and location of the hormetic dose range, but also with the amplitude of stimulation (Belz and Piepho 2012). The two above functions are statistically eligible to model a wide range of different hormetic datasets, independent of species, endpoint, stressor or various levels of biological organization, but with the Cedergreen model (Cedergreen et al. 2005) showing a higher flexibility in modeling due to the second hormesis parameter $a$ (Belz 

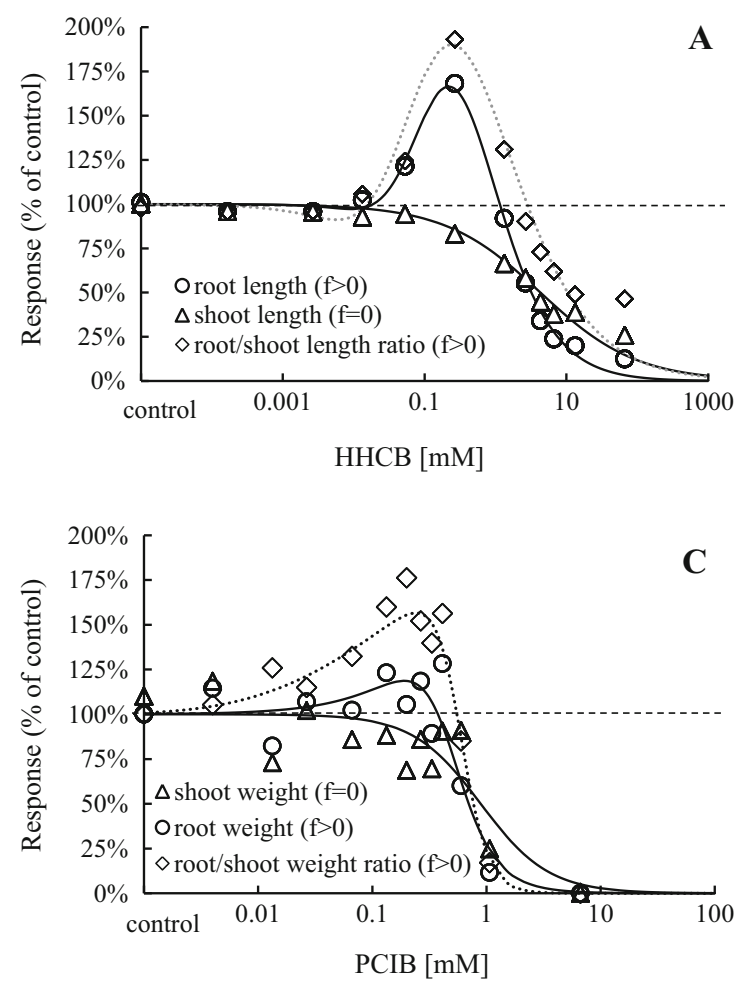

Fig. 8 Responses of Lactuca sativa to 1,3,4,6,7,8-hexahydro4,6,6,7,8,8-hexamethylcyclopenta(g)-2-benzopyran (HHCB), 4-tertoctylphenol; 4-(1,1,3,3-tetramethylbutyl)phenol (octylphenol), and 2-(p-chlorophenoxy)-2-methylpropionic acid (PCIB). Dose-response

and Piepho 2012) (Fig. 8). Using the same models, we were able to model biphasic dose-response relationships also for R/S responses of Lactuca sativa $\mathrm{L}$. to the environmental contaminants HHCB and octylphenol and the auxin inhibitor PCIB calculated from previous research (Belz et al. 2018) or from new experiments (Belz, unpublished data). The curves shown in Fig. 8 provide a preliminary, but illustrative example of significant hormesis in $\mathrm{R} / \mathrm{S}$ ratio and substantiate the demand to consider $\mathrm{R} / \mathrm{S}$ ratio hormesis in assessing above and belowground production/growth responses to stress.

\section{Placing R/S ratio hormesis into an ecological/ environmental context}

Like shoots enable plants to reach required light, root plasticity is an evolution-acquired trait which assists plants in dealing with environmental pressures by foraging for nutrients and water in soil (Grossman and Rice 2012). The $\mathrm{R} / \mathrm{S}$ ratio indicates the potential of supportive functions (water and nutrient uptake) relative to the potential of growth functions (light energy harvest).

The examples presented here show that hormetic R/S dose-response relationships exist and that they can be $U$ -

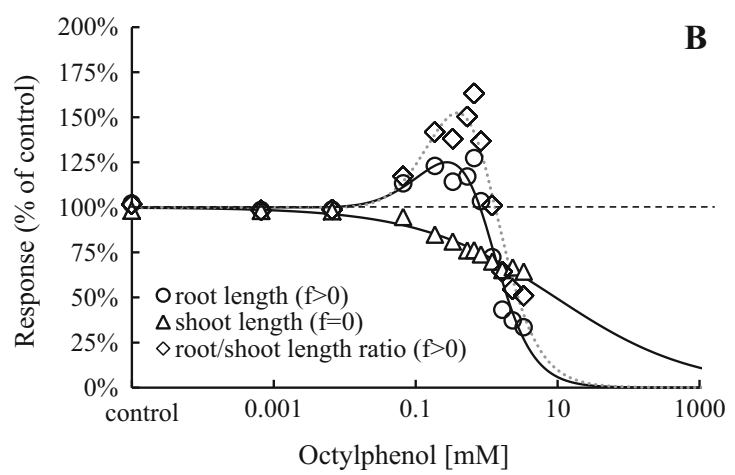

relationships were modeled with Eqs. (1) or (2) for root length $\left(\mathrm{R}_{\text {length }}\right)$, shoot length $\left(\mathrm{S}_{\text {height }}\right)$, or their ratio $\left(\mathrm{R}_{\text {length }} / \mathrm{S}_{\text {height }}\right)$. The parameter $\mathrm{f}$ indicates significant hormesis if $\mathrm{f}>0$ and no hormesis if $\mathrm{f}=0$. Data are from Belz et al. (2018) or Belz (unpublished)

shaped (Figs. 5e, f, 6, 7a) or inverted- $U$-shaped (Figs. 4, $5 \mathrm{a}-\mathrm{d}, \mathrm{f}, 7 \mathrm{~b}-\mathrm{d}, 8)$. At this stage, no conclusions can be drawn as to the reasons explaining this difference due to the lack of relevant dose-response data in the literature. It is also possible that a dose-response relationship for $\mathrm{R} / \mathrm{S}$ ratio is triphasic, such that the non-inverted $U$-shaped curve goes down again at higher doses, (e.g., the weed control agent fenoxaprop-P-ethyl will, at a higher dose, kill the plant, Figs. 6a, 7a). This is a matter of utmost significance in the field of dose-response research which should be validated.

Below-ground competition capacity differs between early- and late-successional species (Xiang et al. 2013; Zangaro et al. 2016). It is generally believed that vegetation in early successional phases shows higher shoot productivity compared to root, whereas vegetation in climax phases shows higher root productivity compared to shoot, such as larch in non-permafrost regions (Kajimoto et al. 2006). Large-seeded species may have an advantage in asymmetric above-ground competition (Mašková and Herben 2018). For example, an old field succession may relate to increased root competitiveness and hence increased R/S ratios of successive dominants (Monk 1966). Although it was initially thought that fast-growing plants show higher phenotypic plasticity than slow-growing 
plants which are not following a strategy for achieving maximum growth rate, this is not a universal case; R/S ratios can be independent of the maximum growth rate (Aikio and Mari Markkola 2002). However, there can be an indirect trade-off between $\mathrm{R} / \mathrm{S}$ plasticity and maximum relative growth rate via a trade-off between maximum relative growth rate and a low-resource growing potential (Aikio and Mari Markkola 2002). After analysing data from 77 studies, no evidence was found for highest plasticity in fast-growing species adapted to high soil nutrient availability or for positive association of plasticity with competitive ability (Reynolds and D'Antonio 1996). These have not been studied in the context of a complete doseresponse continuum, and this may have affected the results. Lack of a complete dose-response assessment may generate misleading results, mostly upon dose-specific sensitivity of each species or group that is compared, i.e., the stress dose levels used can be "low" for the one group but "neutral" (NOAEL) or "high" for the other group. Complete dose-response relationships are highly needed to understand $\mathrm{R} / \mathrm{S}$ ratios from an ecological viewpoint and for selecting species for phytoremediation of specific environmental contaminants (with high $\mathrm{R} / \mathrm{S}$ ratios at low doses for soil contaminants or with low $\mathrm{R} / \mathrm{S}$ ratios at high doses for air contaminants).

Several factors drive the R/S ratio. Plasticity can occur in the context of the optimal partitioning theory, however being constrained by plant ontogeny (Gedroc et al. 1996; Lohier et al. 2014). For example, higher allocation to roots can occur early in ontogeny whereas higher relative shoot growth can occur later on (Gedroc et al. 1996; Lohier et al. 2014). The $\mathrm{R} / \mathrm{S}$ ratio appears as a function of age/size due to different needs for carbon investment, e.g., with regard to canopy closure (Sanquetta et al. 2011). Furthermore, the plasticity of R/S ratios can be a function of different factors, i.e., mycorrhizal versus non-mycorrhizal species, woody perennials versus herbaceous perennials versus annuals, crops versus weeds (Monk 1966; Aikio and Mari Markkola 2002; Bonifas et al. 2005), or even ecotypes with different strategies of resource uptake (Xiang et al. 2013; Zangaro et al. 2016; Mašková and Herben 2018). The lack of a complete dose-response continuum while all constrains are not controlled will generate incomparable results.

Variation in R/S ratios is a common stress response driven by different plant strategies for coping with stress, and can have severe ecological consequences and implications to human welfare (Agathokleous et al. 2016), if this is not a temporary response in an effort to maintain homeostasis. Currently, the implications of the low-dose changes in $\mathrm{R} / \mathrm{S}$ ratios are underexplored, and given the significance of this issue, priority should be given to understanding the low-dose stress effects on $\mathrm{R} / \mathrm{S}$ ratios.
Furthermore, ecological risk assessment based on only a single biomass component is potentially misleading because R/S ratios differ across the complete dose-response continuum and are further driven by a series of factors. The R/S ratio could itself serve as an index of health because there can be competition consequences of $\mathrm{R} / \mathrm{S}$ ratio changes at the community level (Luo et al. 2013).

Framed within a coordinated allocation to biological functions, the whole plant responds to stress and not certain organs (Kleyer and Minden 2015). Estimating carbon storage from either above- or below-ground components can under- or over-estimate the carbon stock (Durigan et al. 2012; Luo et al. 2013). Nowadays with global environmental changes, plants are likely continuously under some environmental pressure. Changes in $\mathrm{R} / \mathrm{S}$ ratios due to both low and high doses of stress in the framework of hormesis suggest that estimates of carbon storage based on single components (above- or below-ground) are likely unrealistic and untrue [Sanquetta et al. 2011; see also the explanation by Zobel and Zobel (2002)]. As these findings suggest that root biomass cannot be realistically predicted from the above-ground biomass using allometric equations, forest tree biomass and carbon storage estimates should be based on both components and under both low and high doses of stress.

\section{Conclusions and future opportunities}

- Several collective examples of hormetic-like dose-response relationships of $R_{d w} / S_{d w}$ and $R_{\text {length }} / S_{\text {height }}$ ratios under stress are herein documented for the first time.

- Hormetic dose-response of $\mathrm{R} / \mathrm{S}$ ratios may be a universal phenomenon, however, the plasticity framing the low-dose responses can be a function of plantspecific strategies of resource uptake.

- Hormetic dose-response of R/S ratios can provide an important perspective in forestry practice and should be considered in bioengineering of hybrids with desirable $\mathrm{R} / \mathrm{S}$ characteristics.

- Hormetic dose-response of $\mathrm{R} / \mathrm{S}$ ratios suggests that ecological risk assessment and carbon storage estimates should incorporate both above- and below-ground components for realistic and true estimates.

- Hormetic dose-response studies can provide a unique opportunity for assessing the ecological impacts of environmental contaminants, with potential incorporation of $\mathrm{R} / \mathrm{S}$ ratios into the risk assessment as an integrated endpoint. R/S ratios can be also considered within a hormetic context for deriving more robust critical levels/loads for the protection of vegetation against environmental pollution. 
- The current scientific literature of $\mathrm{R} / \mathrm{S}$ response to stress suffers from dose-response limitations, with the major limitation being a lack of narrowly-spaced doses across the full dose-response continuum. This study provides a fundamental base for enhancing experimental design to understand $\mathrm{R} / \mathrm{S}$ ratios in the context of doseresponse relationship.

Open Access This article is distributed under the terms of the Creative Commons Attribution 4.0 International License (http://crea tivecommons.org/licenses/by/4.0/), which permits unrestricted use, distribution, and reproduction in any medium, provided you give appropriate credit to the original author(s) and the source, provide a link to the Creative Commons license, and indicate if changes were made.

\section{References}

Abbas T, Nadeem MA, Tanveer A, Zohaib A (2016) Low doses of fenoxaprop-p-ethyl cause hormesis in littleseed canarygrass and wild oat. Planta Daninha 34:527-533. https://doi.org/10.1590/ s0100-83582016340300013

Agathokleous E (2018) Environmental hormesis, a fundamental nonmonotonic biological phenomenon with implications in ecotoxicology and environmental safety. Ecotoxicol Environ Saf 148:1042-1053. https://doi.org/10.1016/j.ecoenv.2017.12.003

Agathokleous E, Kitao M (2018) Ethylenediurea (EDU) induces hormesis in plants. Dose-Response 16:2. https://doi.org/10.1177/ 1559325818765280

Agathokleous E, Saitanis CJ, Wang X, Watanabe M, Koike T (2016) A review study on past 40 years of research on effects of tropospheric $\mathrm{O}_{3}$ on belowground structure, functioning, and processes of trees: a linkage with potential ecological implications. Water Air Soil Pollut 227:33. https://doi.org/10.1007/ s11270-015-2715-9

Agathokleous E, Kitao M, Calabrese EJ (2018a) Emission of volatile organic compounds from plants shows a biphasic pattern within an hormetic context. Environ Pollut 239:318-321. https://doi. org/10.1016/j.envpol.2018.04.031

Agathokleous E, Kitao M, Calabrese EJ (2018b) The rare earth element (REE) lanthanum (La) induces hormesis in plants. Environ Pollut 238:1044-1047. https://doi.org/10.1016/j.envpol. 2018.02.068

Agathokleous E, Kitao M, Calabrese EJ (2018c) Human and veterinary pharmaceuticals induce hormesis in plants: scientific and regulatory issues and an environmental perspective. Environ Int 120:489-495. https://doi.org/10.1016/j.envint.2018.08.035

Agathokleous E, Kitao M, Calabrese EJ (2018d) Biphasic effect of abscisic acid on plants: a hormetic viewpoint. Botany 96:637-642. https://doi.org/10.1139/cjb-2018-0076

Agathokleous E, Belz RG, Calatayud V, De Marco A, Hoshika Y, Kitao M, Saitanis CJ, Sicard P, Paoletti E, Calabrese EJ (2019) Predicting the effect of ozone on vegetation via the linear nonthreshold (LNT), threshold and hormetic dose-response models. Sci Total Environ 649:61-74. https://doi.org/10.1016/j.scitotenv. 2018.08.264

Agren GI, Franklin O (2003) Root:shoot ratios, optimization and nitrogen productivity. Ann Bot 92:795-800. https://doi.org/10. 1093/aob/mcg203

Aikio S, Mari Markkola A (2002) Optimality and phenotypic plasticity of shoot-to-root ratio under variable light and nutrient availabilities. Evolut Ecol 16:67-76. https://doi.org/10.1023/A: 1016096309637

An M, Johnson IR, Lovett JV (1993) Mathematical modeling of allelopathy: biological response to allelochemicals and its interpretation. J Chem Ecol 19:2379-2388

Anav A, De Marco A, Proietti C, Alessandri A, Dell'Aquila A, Cionni I, Friedlingstein P, Khvorostyanov D, Menut L, Paoletti E, Sicard P, Sitch S, Vitale M (2016) Comparing concentrationbased (AOT40) and stomatal uptake (PODY) metrics for ozone risk assessment to European forests. Glob Change Biol 22:1608-1627. https://doi.org/10.1111/gcb.13138

Bastien D, Philippe D, Alodie B, Marie-Laure F (2018) How cadmium affects the fitness and the glucosinolate content of oilseed rape plantlets. Environ Exp Bot 155:185-194. https://doi. org/10.1016/j.envexpbot.2018.06.008

Belz RG, Duke SO (2017) Herbicide-Mediated Hormesis. In: Duke SO, Kudsk P, Solomon K (eds) Pesticide dose: effects on the environment and target and non-target organisms. American Chemical Society, Washington, pp 135-148

Belz RG, Leberle C (2012) Low dose responses of different glyphosate formulations on plants. In: 25th German conference on weed biology and weed control, 13-15 March 2012. JuliusKühn-Archiv, Braunschweig, pp 427-434

Belz RG, Piepho H-P (2012) Modeling effective dosages in hormetic dose-response studies. PLoS ONE 7:e33432. https://doi.org/10. 1371/journal.pone.0033432

Belz RG, Piepho HP (2013) Variability of hormetic dose responses of the antiauxin PCIB on Lactuca sativa in a plant bioassay. Weed Res 53:418-428. https://doi.org/10.1111/wre.12038

Belz RG, Piepho H-P (2015) Statistical modeling of the hormetic dose zone and the toxic potency completes the quantitative description of hormetic dose responses. Environ Toxicol Chem 34:1169-1177. https://doi.org/10.1002/etc.2857

Belz RG, Piepho H-P (2017) Predicting biphasic responses in binary mixtures: pelargonic acid versus glyphosate. Chemosphere 178:88-98. https://doi.org/10.1016/j.chemosphere.2017.03.047

Belz RG, Cedergreen N, Sørensen H (2008) Hormesis in mixturescan it be predicted? Sci Total Environ 404:77-87. https://doi.org/ 10.1016/j.scitotenv.2008.06.008

Belz RG, Patama M, Sinkkonen A (2018) Low doses of six toxicants change plant size distribution in dense populations of Lactuca sativa. Sci Total Environ 631-632:510-523. https://doi.org/10. 1016/j.scitotenv.2018.02.336

Bonifas KD, Walters DT, Cassman KG, Lindquist JL (2005) Nitrogen supply affects root:shoot ratio in corn and velvetleaf (Abutilon theophrasti). Weed Sci 53:670-675. https://doi.org/10.1614/WS05-002R.1

Brain P, Cousens R (1989) An equation to describe dose responses where there is stimulation of growth at low doses. Weed Res 29:93-96. https://doi.org/10.1111/j.1365-3180.1989.tb00845.x

Calabrese EJ, Blain RB (2009) Hormesis and plant biology. Environ Pollut 157:42-48. https://doi.org/10.1016/j.envpol.2008.07.028

Calabrese EJ, Blain RB (2011) The hormesis database: the occurrence of hormetic dose responses in the toxicological literature. Regul Toxicol Pharmacol 61:73-81. https://doi.org/10.1016/j.yrtph. 2011.06.003

Cap MC, Eşen D (2018) Effects of application date and rate of foliarapplied glyphosate on pine seedlings in Turkey. J For Res 29:583-591. https://doi.org/10.1007/s11676-017-0498-0

Cedergreen N (2008) Herbicides can stimulate plant growth. Weed Res 48:429-438. https://doi.org/10.1111/j.1365-3180.2008. 00646. $\mathrm{x}$

Cedergreen N, Ritz C, Streibig JC (2005) Improved empirical models describing hormesis. Environ Toxicol Chem 24:3166-3172. https://doi.org/10.1897/05-014R.1 
Cedergreen N, Streibig JC, Kudsk P, Mathiassen SM, Duke SO (2007) The occurrence of hormesis in plants and algae. Dose Response 5:150-162. https://doi.org/10.2203/dose-response.06008.Cedergreen

Cedergreen N, Felby C, Porter JR, Streibig JC (2009) Chemical stress can increase crop yield. Field Crops Res 114:54-57. https://doi. org/10.1016/j.fcr.2009.07.003

Chen L, Wang C, Dell B, Zhao Z, Guo J, Xu D, Zeng J (2018) Growth and nutrient dynamics of Betula alnoides seedlings under exponential fertilization. J For Res 29:111-119. https://doi.org/ 10.1007/s11676-017-0427-2

d'Aquino L, de Pinto MC, Nardi L, Morgana M, Tommasi F (2009) Effect of some light rare earth elements on seed germination, seedling growth and antioxidant metabolism in Triticum durum. Chemosphere 75:900-905. https://doi.org/10.1016/j.chemo sphere.2009.01.026

Davidson RL (1969a) Effect of root/leaf temperature differentials on root/shoot ratios in some pasture grasses and clover. Ann Bot 33:561-569. https://doi.org/10.1093/oxfordjournals.aob.a084308

Davidson RL (1969b) Effects of soil nutrients and moisture on root/ shoot ratios in Lolium perenne L. and Trifolium repens L. Ann Bot 33:571-577

Diatloff E, Smith FW, Asher CJ (1995) Rare earth elements and plant growth: III. Responses of corn and mungbean to low concentrations of cerium in dilute, continuously flowing nutrient solutions. J Plant Nutr 18:1991-2003. https://doi.org/10.1080/ 01904169509365039

Duke SO, Cedergreen N, Velini ED, Belz RG (2006) Hormesis: is it an important factor in herbicide use and allelopathy? Outlooks Pest Manag 17:29-33. https://doi.org/10.1564/16feb10

Durigan G, Melo ACG, Brewer JS (2012) The root to shoot ratio of trees from open- and closed-canopy cerrado in south-eastern Brazil. Plant Ecol Divers 5:333-343. https://doi.org/10.1080/ 17550874.2012.691564

Gedroc JJ, McConnaughay KDM, Coleman JS (1996) Plasticity in root/shoot partitioning: optimal, ontogenetic, or both? Funct Ecol 10:44. https://doi.org/10.2307/2390260

Gorni PH, Pacheco AC (2016) Growth promotion and elicitor activity of salicylic acid in Achillea millefolium L. Afr J Biotechnol 15:657-665. https://doi.org/10.5897/ajb2016.15320

Grantz DA, Gunn S, Vu H-B (2006) $\mathrm{O}_{3}$ impacts on plant development: a meta-analysis of root/shoot allocation and growth. Plant Cell Environ 29:1193-1209. https://doi.org/10.1111/j.13653040.2006.01521.x

Grossman JD, Rice KJ (2012) Evolution of root plasticity responses to variation in soil nutrient distribution and concentration. Evol Appl 5:850. https://doi.org/10.1111/J.1752-4571.2012.00263.X

He Y-W, Loh C-S (2000) Cerium and lanthanum promote floral initiation and reproductive growth of Arabidopsis thaliana. Plant Sci 159:117-124. https://doi.org/10.1016/S01689452(00)00338-1

Jin C, Chen Q, Sun R, Zhou Q, Liu J (2009) Eco-toxic effects of sulfadiazine sodium, sulfamonomethoxine sodium and enrofloxacin on wheat, Chinese cabbage and tomato. Ecotoxicology 18:878-885. https://doi.org/10.1007/s10646-009-0349-7

Kajimoto T, Matsuura Y, Osawa A, Abaimov AP, Zyryanova OA, Isaev AP, Yefremov DP, Mori S, Koike T (2006) Size-mass allometry and biomass allocation of two larch species growing on the continuous permafrost region in Siberia. For Ecol Manag 222:314-325. https://doi.org/10.1016/j.foreco.2005.10.031

Kleyer M, Minden V (2015) Why functional ecology should consider all plant organs: an allocation-based perspective. Basic Appl Ecol 16:1-9. https://doi.org/10.1016/j.baae.2014.11.002

Koike T, Kitao M, Quoreshi AM, Matsuura Y (2003) Growth characteristics of root-shoot relations of three birch seedlings raised under different water regimes. Plant Soil 255:303-310. https://doi.org/10.1016/j.foreco.2005.10.031

Kress LW, Skelly JM (1982) Response of several eastern forest tree species to chronic doses of ozone and nitrogen dioxide. Plant Dis 66:1149-1152. https://doi.org/10.1094/PD-66-1149

Li X, Chen L, Forde BG, Davies WJ (2017) The biphasic root growth response to abscisic acid in Arabidopsis involves interaction with ethylene and auxin signalling pathways. Front Plant Sci 8:1493. https://doi.org/10.3389/fpls.2017.01493

Liang C, Wang W (2013) Antioxidant response of soybean seedlings to joint stress of lanthanum and acid rain. Environ Sci Pollut Res 20:8182-8191

Liu Y, Wang Y, Wang F, Liu Y, Cui J, Hu L, Mu K (2008) Control effect of lanthanum against plant disease. J Rare Earths 26:115-120. https://doi.org/10.1016/S1002-0721(08)60049-6

Liu Y, Chen X, Duan S, Feng Y, An M (2011) Mathematical modeling of plant allelopathic hormesis based on ecologicallimiting-factor models. Dose-Response 9:117-129

Lohier T, Jabot F, Meziane D, Shipley B, Reich PB, Deffuant G (2014) Explaining ontogenetic shifts in root-shoot scaling with transient dynamics. Ann Bot 114:513-524. https://doi.org/10. 1093/aob/mcu128

Luo W, Jiang Y, Lü X, Wang X, Li M-H, Bai E, Han X, Xu Z (2013) Patterns of plant biomass allocation in temperate grasslands across a 2500-km transect in Northern China. PLoS ONE 8:e71749. https://doi.org/10.1371/journal.pone.0071749

Ma Y, Zou H, Gu H, Shi D, Gao W, Zhang Y, Xie Y (2017) Stimulatory effect of lanthanum nitrate on the root tuber yield of Pseudostellaria heterophylla via improved photosynthetic characteristics. J Rare Earths 35:610-620. https://doi.org/10.1016/ S1002-0721(17)60954-2

Mašková T, Herben T (2018) Root:shoot ratio in developing seedlings: how seedlings change their allocation in response to seed mass and ambient nutrient supply. Ecol Evol 8:7143-7150. https://doi.org/10.1002/ece3.4238

Migliore L, Godeas F, De Filippis SP, Mantovi P, Barchi D, Testa C, Rubattu N, Brambilla G (2010a) Hormetic effect(s) of tetracyclines as environmental contaminant on Zea mays. Environ Pollut 158:129-134. https://doi.org/10.1016/j.envpol.2009.07. 039

Migliore L, Rotini A, Cerioli NL, Cozzolino S, Fiori M (2010b) Phytotoxic antibiotic sulfadimethoxine elicits a complex hormetic response in the weed Lythrum salicaria L. Dose Response 8:414-427. https://doi.org/10.2203/dose-response.09-033. Migliore

Minden V, Deloy A, Volkert AM, Leonhardt SD, Pufal G (2017) Antibiotics impact plant traits, even at small concentrations. AoB Plants 9:plx010. https://doi.org/10.1093/aobpla/plx010

Monk C (1966) Ecological importance of root/shoot ratios. Bull Torrey Bot Club 93:402. https://doi.org/10.2307/2483412

Pan M, Chu LM (2016) Phytotoxicity of veterinary antibiotics to seed germination and root elongation of crops. Ecotoxicol Environ Saf 126:228-237. https://doi.org/10.1016/j.ecoenv.2015.12.027

Payne RJ, Dise NB, Stevens CJ, Gowing DJ, Partners BEGIN (2013) Impact of nitrogen deposition at the species level. PNAS 110:984-987

Reynolds HL, D'Antonio C (1996) The ecological significance of plasticity in root weight ratio in response to nitrogen: opinion. Plant Soil 185:75-97. https://doi.org/10.1007/BF02257566

Sanquetta CR, Corte APD, da Silva F (2011) Biomass expansion factor and root-to-shoot ratio for Pinus in Brazil. Carb Bal Manag 6:6. https://doi.org/10.1186/1750-0680-6-6

Schabenberger O, Birch JB (2001) Statistical dose-response models with hormetic effects. Hum Ecol Risk Assess 7:891-908

Schabenberger O, Tharp BE, Kells JJ, Penner D (1999) Statistical tests for hormesis and effective dosages in herbicide dose 
response. Agron J 91:713-721. https://doi.org/10.2134/ agronj1999.914713x

Sicard P, Anav A, De Marco A, Paoletti E (2017) Projected global ground-level ozone impacts on vegetation under different emission and climate scenarios. Atmos Chem Phys 17:12177-12196

Sugai T, Kam D-G, Agathokleous E, Watanabe M, Kita K, Koike T (2018) Growth and photosynthetic response of two larches exposed to $\mathrm{O}_{3}$ mixing ratios ranging from pre-industrial to near future. Photosynthetica 56:901-910. https://doi.org/10.1007/ s11099-017-0747-7

US EPA (2018) Strengthening transparency in regulatory science. Federal Regist 83:18768-18774

Waman AA, Bohra P, Norman A (2018) Chemical pre-treatments improve seed germination and seedling growth in Semecarpus kurzii: an ethnomedicinally important plant. J For Res 29:1283-1289. https://doi.org/10.1007/s11676-017-0562-9

Wang C-R, Tian Y, Wang X-R, Yu HX, Lu XW, Wang C, Wang H (2010) Hormesis effects and implicative application in assessment of lead-contaminated soils in roots of Vicia faba seedlings. Chemosphere 80:965-971. https://doi.org/10.1016/j.chemo sphere.2010.05.049

Wilson JB (1988) A review of evidence on the control of shoot:root ratio, in relation to models. Ann Bot 61:433-449. https://doi.org/ 10.1093/oxfordjournals.aob.a087575

Wu P, Ma X, Tigabu M, Huang Y, Zhou L, Cai L, Hou X, Oden PC (2014) Comparative growth, dry matter accumulation and photosynthetic rate of seven species of Eucalypt in response to phosphorus supply. J For Res 25:377-383. https://doi.org/10. 1007/s11676-014-0465-y

Xiang W, Wu W, Tong J, Deng X, Tian D, Zhang L, Liu C, Peng C (2013) Differences in fine root traits between early and latesuccessional tree species in a Chinese subtropical forest. Forestry 89:343-351. https://doi.org/10.1093/forestry/cpt003

Xie X, Zhou Q, He Z, Bao Y (2010) Physiological and potential genetic toxicity of chlortetracycline as an emerging pollutant in wheat (Triticum aestivum L.). Environ Toxicol Chem 29:922-928. https://doi.org/10.1002/etc.79

Xie X, Zhou Q, Lin D, Guo J, Bao Y (2011) Toxic effect of tetracycline exposure on growth, antioxidative and genetic indices of wheat (Triticum aestivum L.). Environ Sci Pollut Res 18:566-575. https://doi.org/10.1007/s11356-010-0398-8

Zangaro W, Lescano LEAM, Matsuura EM, Rondina ABL, Nogueira MA (2016) Differences between root traits of early- and latesuccessional trees influence below-ground competition and seedling establishment. J Trop Ecol 32:300-313. https://doi. org/10.1017/S0266467416000274

Zhou J, Guo L, Zhang J, Zhou S, Yang G, Zhao M, Huang L (2011) Effects of $\mathrm{LaCl}_{3}$ on photosynthesis and the accumulation of tanshinones and salvianolic acids in Salvia miltiorrhiza seedlings. J Rare Earths 29:494-498. https://doi.org/10.1016/S10020721(10)60486-3

Zobel M, Zobel K (2002) Studying plant competition: from root biomass to general aims. J Ecol 90:578-580. https://doi.org/10. 1046/j.1365-2745.2002.00693.x 